parallel approaches may be necessary and may already be used by GPs in clinical practice. In one approach the GP could ask in a first step if chest pain is caused by myocardial ischaemia and, if the answer is yes, decide on a second step if the situation should be classified as 'acute' or 'stable'. In another approach GPs may ask in every patient with chest pain if there are any red flags indicative for ACS or other conditions requiring urgent admission to hospital. While the MHS aims to support the first approach it does not substitute the second.

Lastly, Djasmo et al state that our study does not prove that the MHS performs better than GPs' own judgment based on common practice. We agree that such a comparison would be an important step in the evaluation of the MHS. Even more interesting would be an impact study investigating the effect of using the MHS on outcomes relevant to patients, like mortality. However, the primary aim of our study was to test the robustness of the MHS. We are currently working on an analysis comparing different diagnostic strategies based on the MHS, GPs' assessments, and combinations of both. Since this will be a secondary analysis and since the study was not powered to answer these questions, results will be explanatory. A major concern in future studies will be the sample size. Let us assume that the sensitivity of GPs' assessments would be $85 \%$ and that an increase in sensitivity of $5 \%$ would be judged as clinically relevant. Based on these assumptions, and the prevalence of $\mathrm{CHD}$ in primary care, a sample size of about 6000 patients would be necessary to compare these two diagnostic tests in an adequately powered study using a paired design. ${ }^{7}$ Necessary sample sizes for impact studies using outcomes relevant to patients may even be higher. We are not sure if these studies will ever be conducted and assume that recommendations must be based on the limited evidence we have so far.

\section{Jörg Haasenritter,}

University of Marburg, Department of General, Practice/Family Medicine, Karl-von-Frisch-Str. 4, Marburg, 35043, Germany.

\section{E-mail: haasenrilastaff.uni-marburg.de}

\section{Stefan Bösner,}

University of Marburg, Department of General Practice, Preventive and Rehabilitation Medicine, Marburg, Germany.
Norbert Donner-Banzhoff,

University of Marburg, Department of General, Practice/Family Medicine, Marburg, Germany.

\section{REFERENCES}

1. Haasenritter J, Bösner S, Vaucher P, et al. Ruling out coronary heart disease in primary care: external validation of a clinical prediction rule. Br J Gen Pract 2012; DOI: 10.3399/bjgp12X649106.

2. McGinn T, Wyer PC, Newman TB, et al. Tips for learners of evidence-based medicine: 3 . Measures of observer variability (kappa statistic). CMAJ 2004; 171(11): 1369-1373.

3. Viera AJ, Garrett JM. Understanding interobserver agreement: the kappa statistic. Fam Med 2005; 37(5): 360-363

4. Ecollan P, Collet J, Boon G, et al. Pre-hospital detection of acute myocardial infarction with ultrarapid human fatty acid-binding protein (H-FABP) immunoassay. Int J Cardiol 2007; 119(3): 349-354.

5. Planer D, Leibowitz D, Paltiel O, et al. The diagnostic value of troponin $T$ testing in the community setting. Int J Cardiol 2006; 107(3): 369-375.

6. Bruins Slot MHE, Reitsma JB, Rutten FH, et al. Heart-type fatty acid-binding protein in the early diagnosis of acute myocardial infarction: a systematic review and meta-analysis. Heart 2010; 96(24): 1957-1963.

7. Li J, Fine J. On sample size for sensitivity and specificity in prospective diagnostic accuracy studies. Stat Med 2004; 23(16): 2537-2550.

DOI: 10.3399/bjgp12X654489

\section{Scent of a patient: an underestimated role in clinical practice?}

Martina Kelly describes well the ways in which doctors use their sense of smell, including in recognising infection. ' As well as the infections she describes, I would suggest that from my experience there can be a distinct smell in a patient with some upper and lower respiratory tract infections. When my son was 2-yearsold he developed rapid onset of fever, earache, and he smelt distinctly bacterially infected'. It was the latter that made me seek medical attention the same evening. He was prescribed amoxicillin and within 12 hours was afebrile, in less pain, and no longer smelt as if he was rotting; he went to nursery and I went to work. I had a clear conscience believing that he did not have a viral infection that he may spread to his peers at nursery.

Perhaps related, I know that taste comes into my decision making to use antibiotics.
If a patient describes their sputum or nasal discharge as tasting foul I am more likely to resort to prescribing antibiotics. There will sometimes be an associated odour in such cases.

In this age of guidelines rightly helping us to limit our use of antibiotics, I wonder if smell would be a helpful sign to contribute to decision making. However, I suspect it will never end up in the guidelines due to a lack of randomised controlled trials to provide the evidence required.

\section{Victoria Holt,}

48 Constantine Road, London, NW3 2NE. E-mail: vholtalineone.net

\section{REFERENCE}

1. Kelly M. Scent of a patient: an underestimated role in clinical practice? Br J Gen Pract 2012; 62(600): 378 .

\section{Primary care of children: the unique role of GPs}

The editorial on child health in the July issue brings up several points that probably need expanding ${ }^{1}$ as it is hugely important to the whole essence of family medicine and its future.

- How many general practice vocational training schemes do not offer paediatrics as a core element of training and how many doctors in training now do a paediatric exam to show competency?

- The out-of-hours services are staffed by GPs but many ill children never get past the triage system and, anecdotally, parents want more than telephone advice and so vote with their feet and turn up in A\&E. The most deprived households are likely to be car-free and as such unable to get to remote out-of-hours bases, but do not fit visiting criteria set by the out-of-hours companies. How can these conundrums be solved?

- Pregnant women in our area are directed away from seeing their GP; again anecdotally many women seem not to be aware of folic acid or vitamin $D$ advice prior to their pregnancy. We need to address this in contraceptive reviews.

- There are now waiting lists for paediatric outpatients that were rare in the past 